\title{
Blockchain-Driven Customer Order Management
}

\begin{tabular}{|r|l|}
\hline Journal: & International Journal of Operations and Production Management \\
\hline Manuscript ID & IJOPM-01-2019-0100.R2 \\
\hline Manuscript Type: & Research Paper \\
\hline Keywords: & $\begin{array}{l}\text { Blockchain, Digital Technology, Supply chain, Resource based view } \\
\text { (RBV), Information processing theory (IPT) }\end{array}$ \\
\hline \multicolumn{2}{|l}{} \\
\hline
\end{tabular}

\section{SCHOLARONE \\ Manuscripts}




\title{
Blockchain-Driven Customer Order Management
}

\begin{abstract}
Purpose: This study investigates the effects of Blockchain on the customer order management process and operations. There is limited understanding of the use and benefits of Blockchain on supply chains, and less so at processes level. To date there is not research on the effects of Blockchain in the customer order management process.

Method: A twofold method is followed. First, a Blockchain is programmed and implemented in a large international firm. Second, a series of simulations are built based on three scenarios: current with no-Blockchain, 1yr and 5yr Blockchain use.

Findings: Blockchain improves the efficiency of the process: it reduces the number of operations, reduces the average time of orders in the system, reduces workload, shows traceability of orders and improves visibility to various supply chain participants.

Contributions: This is the first study that demonstrates with real data from an industrial firm the effects of Blockchain on the efficiency gains, the reduction in the number of operations and human-processing savings. A detailed description of the Blockchain implementation is provided. This paper contributes to the resource-based view of the firm, by demonstrating two new competitive valuable capabilities and a new dynamic capability that organisations develop when implementing and using Blockchain in a supply-demand process. It also contributes to the information processing theory by highlighting the analytics capabilities required to sustain Blockchain-related operations.

Limitations: The research is based on a single in-depth case that has the scope to be tested in other contexts in future.
\end{abstract}

Keywords: Blockchain, digital technology, supply chain, customer order management, resource-based view, information processing theory

\section{INTRODUCTION}

Inaccuracy of specifications, volume variability, frequent change requests, a lack of clarity and diverse safety specifications are among the most common customer order management problems in supply chains. These problems are generally intensified by other resource-based problems such as, multiple information systems, manual input, numerous customer communication channels, and varied cultural and human practices and behaviours. The combination of problems consequently leads to lack of traceability of orders, lack of visibility for customers and supply chain participants together with lack of reliability, ultimately leading to trust shortages and inefficient operations and transactions (Carter and Koh, 2018).

Traceability is becoming a fundamental differentiator in many supply chain industries including the agrifood sector (Feng, 2016; Aitken, 2017), the health and pharmaceutical sector (Rotunno, Cesarotti, Bellman, Introna and Benedetti, 2014; Eklab et al., 2016) and high-value goods (Maurer, 2017). The lack of traceability, leads to a lack of transparency and visibility, affecting the reliability and trust of operations. For instance, the salmonella outbreak linked to raw chicken products affected nearly a hundred people in more than eight states of the United States of America. If only the producer and its supply chain could have been traced and disclosed, it could have saved many people from falling ill and being hospitalised (CDCP, 2018). This situation urgently calls for a better information-sharing and verifiability (Saberi, Kouhizadeh, Sarkis and Shen, 2018).

Safety of the data is another issue: the majority of supply chains rely on centralised information systems such as enterprise resource planning. Centralised information systems like these leaves the entire system exposed to error, hacking or attack (Dong, Zhou, Liu, Shen, Xu and Luo, 2017). 
Blockchain - a distributed digital ledger technology - ensures traceability, transparency, and security; it is showing some potential promises in terms of easing some supply chain problems (Mendling, Weber, van der Aalst, Brocke, Cabanillas, Daniel and Dustdar, 2017).

Blockchain is one of the top five digital technologies forecast to change the way we operate and live (Brennan, et al., 2015; Tapscott and Tapscott, 2017). By 2027, 10 percent of the global GDP will be stored on Blockchain (World Economic Forum, 2015). At the world economic forum in Davos, Blockchain stood out as a priority technology with significant implications for people, businesses and the wider society (Carter and Koh, 2018). Countries such as Germany and China have placed Blockchain as at the core of their 2020 and 2025 national action plans (respectively) to become digital industry leaders (Xu, Xu and Li, 2018; Sartor, Orzes, Nassimbeni, Jia and Lamming, 2015). Tapscott and Tapscott (2017) argue that 'Blockchain allows companies to eliminate transaction costs and use resources on the outside as easily as resources on the inside'. Carson, et al (2018) highlight that the value of Blockchain will eventually shift from driving cost reductions to enabling entirely new business models and revenue streams. Power Ledger is an example of a decentralised energy-sharing company built on Blockchain technology, where energy producers (such as solar-panel owners) trade their extra electricity, generated locally, to neighbours in exchange for real-time payment carried out transparently on Blockchain (Ethereum). Implementations in Australia and New Zealand resulted in savings of up to $\$ 900$ on users' yearly electricity bills and doubled the savings of solar panel owners (Powerledger, 2017).

Blockchain is a public and incorruptible platform where users upload self-executing programs and can verify all past and current states of the system. There is great interest in Blockchain because of its architecture of traceability, transparency (visibility), security (resilience) and anonymity, requiring neither trust between the participants nor a regulating intermediary (Yli-Huumo et al, 2016; Saberi, Kouhizadeh, Sarkis and Shen, 2018). The information track record is held in a tamper-proof database that is available for inspection on demand by interested parties (Swan, 2017). Blockchain has four important attributes that can benefit a business application (Palfreyman, 2016; Carter and Koh, 2018).

- Immutability: transactions, once validated, cannot be altered by malicious actors.

- Traceability: there is a complete and transparent audit trail of transaction history.

- Consensus: there is a single record agreed upon by all participants to prevent disputes.

- Automation: commands and transactions can execute themselves on previously set conditions.

Some scepticism around this relatively new digital technology is observed. While some argue that Blockchain is nothing more than a mere data structure with multiple user ownership and control (Karafiloski, and Mishev, 2017), others suggest that 'Blockchain is an innovative technology in search of use cases' (Glaser, 2017). One plausible explanation is that the early applications of Blockchain - from 2008 to 2014 were devoted to cryptocurrencies (Scott and Miau, 2018). Despite criticism, the popularity of Blockchain is growing exponentially and applications of Blockchain are broadened to different contexts. In 2015, fewer than 100 documents were found in the Scopus Database, in the subsequent year this figure doubled, by the end of 2018 more than 750 documents were found, and finally by early 2019 more than 820 documents had been identified.

To date, there are not academic studies or industrial cases demonstrating the effects of blockchain implementations on punctuated processes of the supply chain, particularly in customer order management. Moreover, existing studies lack of an understanding of the capabilities and effects of Blockchain's implementations on already existing operations, systems and capabilities.

The objective of this study is to identify the effects of Blockchain on the operations of the customer order management process of a supply chain. A parallel objective, is to provide a detailed implementation of Blockchain in a customer order management process.

The following sections discuss the theoretical foundations of the study. This continues with the research design taken to answer these questions including the selection of methods. The results lead to a set of findings that shows how blockchain implementation could advance management of the theory and practices in the 
supply chains of industrial firms. Finally, this paper concludes with contributions to the advancement of the blockchain theory, implications for practice and limitations.

\section{THEORETICAL FOUNDATIONS}

\section{A. Blockchain Applications}

Blockchain is a revolutionary technology that is largely applied in the financial sector particularly in cryptocurrencies such as Bitcoin (Glaser and Bezzenberger, 2015; Holotiuk et al., 2017; Yermack, 2017, Miau and Yang, 2018) and smart contracts (Alharby and van Moorsel, 2017). Outside cryptocurrencies, a limited understanding of the uses of blockchain is evident (Avital et al., 2016; Risius and Spohrer, 2017).

Nowinski and Kozma (2017) foresee a trend that the research body on applications will explode in the coming years. Applications could include services in supply chain management, insurance, digital knowledge management and e-commerce (Glaser, 2017).

The majority of applications of this digital technology are at a nascent stage. Several cases demonstrate the use of blockchain; nonetheless, learning from these applications has changed the way that companies operate. The impact of blockchain on business models remains extremely interesting to both industrialists and scholars (Risius and Spohrer, 2017).

Beyond the financial applications (Brown, 2018), blockchain has recently been implemented and tested in a few other contexts such as health (Eklab et al., 2016), energy (Naudin, 2017), land registry (Landmateriet, 2017, (Vorick and Champine, 2014; Bocovich et al., 2017), automotive (Shieber, 2017), education (MIT, 2018), high-value assets (Everledger), data management (Zyskind et al., 2015), land administration, (Conoscenti et al., 2016), food (Steiner and Baker, 2015) and other marketplace economic models (Sun et al., 2016, McConaghy and Holtzman, 2015). However, the majority of these implementations are reduced to early blockchain implementation stages, with little information disclosed about the effects of blockchain on their operations, performance and outcomes. Only a few successful cases show the impact of the blockchain technology on business performance.

For instance, Ripple orchestrated one of the earliest blockchain implementations in the financial sector (Nowinski and Kozma, 2017). Partnering with Apple and Santander, Ripple facilitates inter-bank payments in real time at lower fees. It leverages the blockchain to create a frictionless fiat currency transfer across entities and borders. The system is implemented and operates transfers, with more than thirty banks involved and more than a hundred institutional customers worldwide. The results of Ripple's Blockchain show a more efficient cost structure for money transfers, resulting in transaction fees that are lower than those associated with traditional systems. The first pilot test saw savings of 40-70 per cent on the entire operation compared to traditional foreign exchange providers. Moreover, an average transfer took a little over two minutes, as opposed to the average of two to three days of traditional bank transfers (Ripple, 2018).

Provenance is another successful implementation case of Blockchain. The company facilitates retailers to provide customers with reliable data to track fresh produce (such as seafood, coconut, cotton, etc.) from origin to supermarket. In these cases, transparency and validity of sustainable practices are paramount for customers, producers and retailers (Steiner and Baker, 2015).

\section{B. Blockchain in Supply Chains}

Blockchain is an open platform that allows companies to build their own applications. Its versatility and vast array of applications recommend its use in the supply chain (Benkler, 2006). Companies are actively exploring how they can leverage blockchain to innovate parts of their business operations in the form of 'private' Blockchains (Davidson et al., 2016). Private Blockchains require neither cryptographic incentives nor proof-of-work as public ones, but access is restricted to the chosen network and its information. There is a fine balance between cost and effectiveness, private Blockchains offer are less expensive as tend to operate in regions within secure business networks. Whereas, public Blockchains are more expensive as they run 
their computational power in secure global networks. (Koetsier, 2017). Public Blockchains are general adopted to operate cryptocurrencies and other valuable transacitons (Kshetri, 2018).

Reducing the complexity and lowering the technical barriers have contributed to the growing popularity of blockchain. Thereby, it is foreseen that Blockchain will increasingly be in competition with the systems of existing organisations and could eventually pose a threat to them as a result of its potential to perform their tasks more efficiently or reliably (Davidson et al., 2016).

It is hypothesised that the value-added from Blockchains resides in the companies' internal value chain (Science, 2016). Blockchain could revolutionise the way supply chains work (Dickinson, 2016). Kshetri (2018) claims that supply chains are believed to be one of the most promising and transformative nonfinancial applications of Blockchain. Bunger (2017) supports that an industrial use-case in supply chains can provide an early return on investment for Blockchain applications.

As information input into the Blockchain is immutable, trust amongst participants is solidified as they can keep track of shipments, deliveries and product quality during transport (Kshetri, 2018). Because of the potential of removing paperwork, middlemen and auditors, costs might be reduced, and efficiency and speed could be improved while broadcasting updated information in real time (Koetsier, 2017). Moreover, Blockchain promises to increase standardisation, automation and transparency based on data and code, and it has the potential to increase productivity and decrease transaction costs, errors and conflicts (Seebacher and Schuritz, 2017). Table I shows Blockchain implementations and outcomes in various industrial cases.

As most companies build and maintain their own supply chain management software, it is difficult to have a global view of goods' status in today's increasingly intricate supply chain networks. This appears to be a tantalising application for Blockchain, as a decentralised distributed database, to increase transparency and information integrity (Gao et al., 2018). In this field, the Blockchain could be used to facilitate the recording of orders and receipts of goods, and the tracking of goods in transport, and to support customer services. Combined with barcodes, GPS, radio-frequency identification (RFID), sensors and the emerging trend of the Internet of Things, Blockchain can enhance goods tracking from origin to customer; in fact, its applications in the supply chain focus on traceability and source tracking (Kim and Laskowski, 2017).

Our literature research shows that Blockchain is applied to a variety of dimensions on supply chains, ranging from designing (growing), making and using to distributing and selling within single or multiple markets. Table I summarises the Blockchain applications in supply chains.

Currently, the foods and goods supply chains are leading Blockchain implementation. Cases demonstrate the implementation of Blockchain on the mainstream supply chains of cotton, coffee and other goods, which use blockchain from the growing, producing to the processing, distribution and retailing stages of the supply chain. Four out of eight applied cases reported in the literature have been used in the foods and goods supply chains. The rest are applications on diverse sectors such as health and safety compliance, high-value assets and automotive. Their blockchain applications are limited to the front end of the supply chains, as in distribution and retailing.

With the exception of the Everledger case, the maturity level of these Blockchain implementations is at the proof of concept stage (see Table I). Most of these successful pilot cases are waiting to be scaled up to understand and study the full potential of the Blockchain in their industrial contexts. Unfortunately, the majority of these studies lack depth of understanding of Blockchain's effects on individual supply chain processes and operations.

To date, no academic studies have demonstrated the effects of Blockchain implementation on punctuated processes of the supply chain. Moreover, existing studies lack an understanding of the behaviours and effects of Blockchain's implementation on existing operations, systems and capabilities.

TABLE I

Blockchain applications in supply chain cases 


\section{The Resource-Based View and the Information Processing Theory}

In pursuit of higher levels of visibility in customer order management, Blockchain is seen as a promising technology to drive competitive advantage - operational efficiency and/or the creation of new revenue models. Blockchain is considered to be a firm's capability that requires intrinsic analytical skills to programme and process information.

Koh, Morris, Ebrahim and Obayi (2016) argue that the resource-based view (RBV) of firms provides a good starting point for conceptualising resource efficiency. According to the RBV, valuable, rare, inimitable and non-substitutable (VRIN) resources, supported by tacit skills and socially complex organisational processes, give firms their competitive advantage (Barney, 1991). However, the competitive advantage described in the RBV is essentially a product of efficient and sustainable production and utilisation of resources. In this case, maximisation of the use of blockchain opens up the traceability and visibility of the customer order management process.

The RBV theory explains the adoption of the capabilities, skills, processes, technology and networks required to implement this digital platform in organizations to enhance their competitive advantage. The analysis of Blockchain through the RBV lenses reflects on the importance of not only evaluating the requisite resources and capacity that underpin the implementation and use of this digital technology, but also more importantly understanding the existing and missing skills and capabilities and the bridge between them. In bridging current and missing capabilities, the RBV provides the theoretical foundation for understanding the dynamic re-adaption of current capabilities (Barney 1991; Koh, Morris, Ebrahim and Obayi, 2016).

In rapidly changing environments as today, the dynamic capabilities equip companies with the ability to integrate, build and reconfigure competencies to provide fast response to changes in their ecosystems (Teece, 2007). Sensing, Sizing and Transforming are foundations that distinguish dynamic capabilities. Sensing is the ability to identify and filter opportunities, e.g. customer innovation. Sezing is ability to assess and manage complementors and co-specialisation for reconfiguring assets and processes to respond to chosen opportunities. Transforming is the ability to learn, manage knowledge and decompose/decentralize structures to assist reconfiguration (Teece, 2007).

Blockchain is ultimately an information technology; thus, the information processing theory (IPT) complements the understanding of the effects of Blockchain on supply chain processes. The IPT focuses on the link between environmental uncertainty (collaboration and information-sharing in supply chains), information processing (analytics capability) and the adaptation needs of organisations (organisational flexibility and market volatility). The information processing (the analytics capability) of an organisation is complemented with organisational flexibility. Higher levels of supply chain transparency, measured by supply-demand visibility, require stronger information processing, hereafter referred to as 'analytics capabilities' (Srinivasan and Swink, 2017; Zhu et al., 2018). Blockchain technology provides significant visibility (Swan, 2017; Karafiloski and Mishev, 2017) but requires more specialised analytics capabilities within a given context. The analytics capabilities are continuously learnt and further developed/improved until they evolved within a particular context and become dynamic capabilities through the evolution of operational routines. The operational routines evolve though three learning mechanisms - experience accumulation, knowledge articulation and knowledge codification process (Zollo and Winter, 2002).

While the RBV provides a framework to understand the capabilities, skills and processes that must be built and re-adapted to drive competitive advantage through Blockchain in supply chain processes, the IPT advances the RBV as a potential dynamic capability by evaluating the information processing needs in blockchain implementation. For instance, the competitiveness of private versus public Blockchain technologies could be evaluated using IPT; similarly, the evaluation of the consequent analytical capabilities required for each Blockchain technology. Greater transparency requires the use of public Blockchain 
technologies and complex analytics capabilities to manage environmental uncertainty (public competitiveness, collaboration and information-sharing), whereas private Blockchain enhances private supply chain competitiveness and therefore requires less complex analytical capabilities. From the information processing theory (IPT), Saberi, Kouhizadeh, Sarkis and Shen (2018) call for more studies to understand how supply chain processes are affected by the implementation of Blockchain technology.

Our research enquiry is also prompted by hearing repeated problems from industrialists associated with the lack of understanding of this digital technology. Common problems include pressure to become more digital and a lack of understanding about the benefits, opportunities, short- and long-term investments and the consequences for existing technologies. There is still a [mis]conception about more digital capabilities leading to higher competitive advantage. One IT director of a multinational organisation pointed out: '...it is difficult to see how Blockchain will change the way WE operate in our context? The tasks, the skills, the processes, etc. At the end of the day, it is difficult to gauge if Blockchain would be worth the investment...' One supply chain manager added: '...Blockchain vendors are very keen to come and sell you their solutions (generally at astronomical prices), but they rarely explain in detail the impact of blockchain - in our processes, changes in operations, systems and costs.' Looking at these industry problems from an academic perspective, the confusion and lack of understanding are not surprising. The literature sheds very little light on the effects of Blockchain in the operations of a supply-demand chain. In response to this series of problems, we set up an experimental study. The objective of this study was to identify the effects of blockchain on operations in a supply-demand chain.

In setting up the research, the first set of premises was the lack of investment in, and credibility of, Blockchain in the supply chain of an international industrial manufacturer. In formulating our first research question, we took the resource-based view theory and assumed a lack of budget to acquire the Blockchain technology and the necessary skills and expertise. Therefore, our first question was:

RQ1. 'How could a Blockchain program be coded with basic in-house resources and capabilities?'

This led us to a subsequent line of enquiry:

RQ2. 'What are the effects of a distributed ledger platform - Blockchain - on the customer order management operations?'

\section{METHOD}

The emerging nature of research on Blockchains in supply chains was formalised not long after 2015; however, few studies have been conducted beyond smart contracts in a supplier-provider context (Dickinson, 2016; Vorabutra, 2016; Scott and Miau, 2018). Given the emerging nature of knowledge on this topic, an exploratory research method was chosen as the right methodological fit to investigate our line of enquiry (Edmonson and McManus, 2007). The exploratory research based on case studies enables an in-depth understanding of the phenomenon that could lead to theory development through elaboration (Eisenhardt, 1989; Ketokivi and Choi, 2014; Gehman, Glaser, Eisenhardt, Gioia, Langley, and Corley, 2018). An in-depth case study method was selected as the foundational method for this research because the close proximity to the phenomenon and access to the data (Eisenhardt, 1989).

The logic of this research design revolved around our two research questions. In answering the first research question (RQ1: How could a Blockchain program be coded with basic in-house resources and capabilities (technology/skills)?), we built a 'Pilot' and by programming an in-house Blockchain system and an interface to enable the end-user to communicate with the Blockchain program.

To answer the second research question (RQ2: What are the effects of Blockchain on the operations of a supply-demand chain (particularly in customer order management)?), we used the Blockchain system that developed in RQ1 and then we developed a series of simulations based on three different scenarios: (1) 'as it is' (current scenario without blockchain); (2) 'as it could be', with the use of blockchain in the first year; 
and (3) 'as it could be', having used Blockchain for five years. Table II summaries the methods and correspondent steps to answer each individual question.

TABLE II

Research design logic: question and associated methods and techniques

\section{A. Unit of Analysis}

To add a precise understanding to the existing body of literature and to control our study, we decided to focus on the implementation and use of Blockchain in a particular process of the supply chain - customer order management. Customer order management was chosen as it is a process that cuts across several internal functions, but also interacts with external agents, such as customers. It is considered to be a good representation of what Blockchain can do in the wider supply chain and it is a process that lends itself to be scaled up and join other processes. Additionally, this process is often seen as the bottleneck to all the information flowing from the early processes of supply chain stages. Methodologically, narrowing the research context to customer order management 'a contained process', not only helps us to reduce complexity but can also increase the validity and reliability of this study.

\section{B. Data Collection}

The single in-depth case study (Yin, 2009) was supported with direct data collection from primary sources at the company case: interviews, shadowing orders, mapping processes, skills and times, and a validation workshop. Secondary sources of data included: customer order reports, customer order modification reports and databases from the last 12 months, task descriptions, ERP reports, Excel reports, customer requirements and monthly/quarterly reports. Secondary data was used to complement and triangulate sources with primary data. The triangulation of data strengthened the validity and reliability of this research.

The primary data collection consisted of more than 63 hours of direct contact:

1. Face-to-face interviews with four out of six Account Coordinators for the customer order management department of the company, the head of supply chain and the head of digital transformation.

2. Shadowing customer orders by direct observation. The researchers followed a sample of orders through the process, mapping the activities and timing them.

The other data collection method that was used over 11 months of the study included:

1. Active remote dyadic (back-and-forth) interactions. For example, multiple questions and clarifications over phone, email and skype.

2. Two validation workshops with four Account Coordinators.

\section{Simulation-based Approach and Theory Elaboration}

A simulation-based approach was adopted to obtain a closer, more significant and detailed understanding of the application and effects of this digital technology in the operations of this in-depth case study. Simulation provides an unparalleled experimentation platform to add realism through a dynamic and systematic set of experimentation (Weick, 1989).

To systematically elaborate theory, this research was guided by the seven-step roadmap for developing theory using a simulation method (Davis, Eisenhardt and Bingham, 2007). 1) It started with the definition of the research question (RQ2). 2). Then, the RBV theory was selected to provide a theoretical ground to explain and compare the findings. 3) The discrete event simulation approach with Simul8 was chosen because it 
provides detailed analysis of transactions (which is core to answering RQ2). 4 \& 5) To create and verify the computational representations and their correspondent logic, the individual process maps were developed to understand the customer order management process (the phenomenon under study). These include placing and amending orders maps for the current state 'as it is' (without blockchain). Then, the maps were verified by every account coordinator, and improvements were continuously made, until they reached a full consensus - in representations and logic. By using a simulation-based approach to build and elaborate theory, a strong emphasis was placed on strengthening the rigour of these computational representations and their correspondent logic, which strengthened the internal validity of this research. 6) Building on strong representations already verified, two further scenarios were developed and tested - 'as it could be', with the use of blockchain in the first year, and 'as it could be', having used blockchain for five years. 7) Finally, these last scenarios were verified using precise empirical data (Davis, Eisenhardt and Bingham, 2007). The findings of the simulation study are shown in the discussion section. The application of Davis, Eisenhardt and Bingham's road map for developing theory into our simulation and case adds realism and strengthens the analytical generalisability of the findings and potentially elaborates or extends a theory (Ketokivi and Choi, 2014).

This is a theory-elaboration type of research. In elaborating theory, the focus is on the contextualised logic of a general theory. It reconciles the general with the particular, in our case Blockchain, in the light of the RBV and dynamic capabilities within a supply-demand context. Unlike theory-building, theory-elaboration does not anticipate the empirical findings - propositions or hypotheses - but elaborates them through the analyses of the findings (Ketokivi and Choi, 2014).

To get a complete understanding, analysis and evaluation of the development and implementation of Blockchain in a supply chain process an in-depth case study is adopted. Differently from other methods such as surveys, in-depth cases could provide access to processes, orders, transactions, and customers' demands among others (Eisenhardt, 1989). Welsh and Lyons (2001) add 'outcomes from individual case studies are not statistically generalisable but analytically generalisable'. The case is a multinational company that has sites, customers and suppliers around the globe, therefore having interactions across parts of the supply chain in different cultural contexts.

\section{III.FOSSORCO}

\section{A. Company Background}

Our study is set in an international industrial manufacturing company specialising in heavy-assets equipment.

At FossorCo (disguised name), an ERP, an in-house collaboration tool, an electronic data interchange (EDI), Excel sheets, customer portals, emails, fax and phone calls are all used to manage customer orders. The associated fragmentation and lack of standardisation result in a slow and inefficient system that is prone to frequent mistakes. Customer orders are highly manual and time-consuming; hence, there is a high investment and operating cost associated with human resources. Additionally, as a result of the laborious manual activities required for each order, processing and response times are long.

The scope of the study is limited to the stream of orders as follows:

- The internal customer transmits an order request to the order management department.

- The order management department checks for and resolves any problems and then approves the order request.

- The order management department relays order specifications to the production team, which proceeds to assemble the components required into the desired product.

\section{B. Process Maps}

The current customer order management typically starts with the customer placing an order. The supplier then either approves or declines the order and provides a response to the customer. If the order is approved, the customer may ask to modify the order and does so by submitting a request to the supplier. Thus, the 
supplier either approves or declines the modification requested depending on how well the modification meets a specific rule set (e.g. the volume fluctuations). Finally, closing this loop, a response is provided to the customer. Often customers make more than one modification to their initial orders; hence, there is an iteration process called order amendment. To simplify the customer order mapping, this was split into two: first, a map for placing orders, and a subsequent one for amending orders.

The 'current placing orders process map' has 36 steps (Figure 1), while the 'current amend-orders process' consist of 20 steps. The process maps for placing orders are included as examples in this paper, but the whole study includes the quantification and analyses both - placing and amending orders.

FIGURE 1. Current placing orders process map

An order can be modified by changing the quantity or the shipment date. To make these changes, there is an established three-rule process set by FossorCo. First, the frozen period: two weeks before the shipment date, when no further changes can be made. Second, the volume fluctuation allowance is the percentage by which a modified order quantity can deviate from the initial order quantity. Third, the recommended fluctuation threshold, which is the percentage deviation between the modified order quantity and initial order quantity that the supplier recommends. For instance, an order is approved if the new quantity falls within the volume fluctuation allowance.

\section{Identified Problems in the Current Processes}

Looking into the problem further, several key issues are evident in mapping the scenario.

1. Amending orders can take many days to be approved. Inefficient communication lines and inadequate scenario-handlers result in long periods of time elapsing before an amendment to an order is approved and modified.

2. Multiple communication channels to place or amend an order, for example, fax, email, phone. A lack of standardisation causes inefficiencies in the system, such as discrepancies in the data collected and the possibility of errors further down the line. This substantially increases customer frustrations and the likelihood of disputes between customer and supplier. For example, accuracy and traceability of modifications are highly unreliable.

3. Multiple rule sets for different orders/customers. Visibility is an issue, as customers do not see the rule sets that are in place when an order or modification goes through the approval process.

4. Extensive manual work. Multiple customers and a lot of manual work involved.

5. Multiple external customers. They need to feel they are in control, which is impossible with the current process.

6. Prolonged grief. Grief refers to the inability to process an order as a result of incomplete or incorrect information. It is the source of many discussions and a significant drain of time for account coordinators.

\section{IV.DESIGNING AND IMPLEMENTING THE FOSSORCO BLOCKCHAIN}

In preparation for programming and implementing the Blockchain for FossorCo, three foundational phases need to be developed. The first phase is the selection of technologies for the company's and clients' needs. Second, there is building the architecture. The third involves designing the blockchain interactions or information flow for placing and amending orders. To secure the programming quality, the 'test-driven development methodology' was followed (Dingsøyr et al., 2012). Table III summaries these three phases and explains the processes and results. 
TABLE III. Blockchain technology selection, architecture and information flow

\section{A. Coding the Blockchain}

In maximising the accuracy and efficiency of coding, we used the 'test-driven development'(TDD) methodology. By following a continuous cycle - coding, testing and refactoring - its unit testing verifies individual units of code to ensure that they work as intended. Thus, this methodology allows external developers to easily understand the codebase (Dingsøyr et al., 2012).

The final version of the Blockchain-enabled customer order management system for FossorCo (back-end and front-end applications) has more than 5,000 line codes and took 15 iterations. Two programmers were involved: one focused on programming the blockchain (back end) and the second on the customer interface (front end).

The customer interface (front end), coded in React, is designed as a straightforward dashboard for collecting customer data (place/modify orders), feeding the blockchain (back end) and presenting the status of orders. This interface gives a complete overview of an order: the order number, quantity, shipment date, order status, who placed/modified the order, when the order was placed/modified and additional comments relating to the order.

\section{B. Using the Blockchain-enabled Customer Order Management System}

The integration of the back-end with the front-end program builds the 'Blockchain-enabled customer order management system', from now on referred to as the 'blockchain solution'. When a new customer organisation is added to the Blockchain solution, predetermined access rights for writing, viewing and/or accessing information to this blockchain solution are set by the customer's organisation and enabled (programmed) by FossorCo.

To achieve a fast and simple status of orders and their traceability history, we designed the dashboards (see Figure 2) with direct company input. The Blockchain solution allows FossorCo's customers to have access to clear informative dashboards. The dashboards open the visibility of orders and their corresponding status. More importantly, they show the 'tamper-proof' traceability history of orders, including: what changes were requested, when the changes were requested, who from the customer's organisation placed/amended an order and the Account Coordinator number. Traceability is a unique differentiator of the blockchain among other databases; Figure 2 shows an example of the placed-order dashboard.

FIGURE 2. Placed order dashboard 
The Blockchain solution impacts the operations of the firm's customer order management process. Thus, it is possible to draw the following findings:

\section{1) Improved the order management process efficiency}

The Blockchain solution considerably improved processing time. While normally it would take $2-4$ days for an order or modification to be processed and approved, the Blockchain solution leads to instantaneous, automatic approval times (including the verification time against set rules) and a reduction in the amount of griefs. Improved efficiency, from 2-4 days to less than 1 minute.

2) Improved traceability of order placed and amended

The Blockchain solution improved the traceability of orders placed/amended at FossorCo. The company never had this open and detailed traceability available for all its transactions in the past. This was achieved through the Access Control file, which secures the integrity of the data and controls and records the access of participants into the Blockchain solution. Now it is impossible for someone to alter previous transactions. Therefore, transactions displayed on a dashboard are traceable back to participants, with date/time and detailed modifications - quantities, specifications, approvals and confirmations (Figure 2).

3) Improved the visibility of the order management process

The visibility of data has been increased and safely opened to FossorCo employees, and its customers' employees in the supply chain, by predetermined access rights for writing, viewing and/or accessing information. These rights were previously set by the customer's organisation and enabled in the Blockchain solution of the firm.

4) It has been proved that the Blockchain solution can be programmed and used to solve real supply chain problems, particularly in the customer order management process, with relatively basic resources and capacity for further scalability.

Coming back to our first research question, the Blockchain solution was programmed and built with simple resources (free-to-test applications) and basic programming skills. It is successfully working in the FossorCo scenario between provider and customers. This Blockchain solution was built with scope for scalability to accommodate more types of product and volumes within a large business context. With the front end and back end working seamlessly, it shows that Hyperledger Composer can be used to build a robust Blockchain network on the Hyperledger Fabric runtime, while React was used to create an aesthetically pleasing customer/user interface. The technology and programming choices, such as the use of the private type of Blockchain, Hyperledger Composer and Hyperledger Fabric, and the TDD methodology, among others, were made to lower learning entry barriers, reduce implementation costs, secure scalability and increase safety and usability.

5) From resources to dynamic capabilities: theory elaboration

During the development of Blockchain at the FossorCo's customer order management, three types of resources emerged - Blockchain technology, knowledge and other resources (see Table IV). Our analysis shows that the more these resources interact and bundle with others, more they evolved into a competitive valuable resource. For instance, the 'tacit and codified knowledge of customers consumption behaviours' formed a complementary bundle with the 'Blockchain design-platform and subroutines'. Because these resources became intertwined and depended on each other, they resulted to be more specialised and rooted into the needs of the company. As a result, this bundled evolved and developed a new RVB competitive valuable capability, defined by Barney (1991) as rare, valuable, inimitable, non-substitutable. It is called 'Blockchain logic \& routines that identify and filter competitive opportunities based on customers consumption behaviours and supply chain flexibility knowledge'. Later, this RBV competitive capability integrates and interacts with other emerging RBV competitive capability - called 'Rules' transformation process based on emerging customers' demands', as a result these two evolved into a dynamic capability called 'Dynamic adaptation of rules and routines by active utilization of new/old learnings. This new dynamic capability has the ability to sense changes into customer consumption patterns through the monitoring of special customer's requests to their orders. Then, it seizes the opportunities according to the 
customer loyalty and supply chain flexibility to accommodate the customer's requests. Finally, it transforms, adapts or creates an existing or new rule to deal with this type of customer's requests like this in future. Therefore, a new Blockchain logic and subroutine are created to process the order (Teece, 2007). In a way, the rules and Blockchain's logic and subroutines learn and adapt in response to new issues in the customer demand, similarly to Zollo and Winter's deliberate learning through dynamic capabilities (2002). This evolution from resources to dynamic capabilities is illustrated in Table IV

TABLE IV. Evolution from resources to dynamic capabilities

\section{VI.DisCUSSIONS BASED ON SIMULATION ANALYSES}

\section{A. Blockchain Effects: A Simulation-based Approach}

The Blockchain solution built for FossorCo improved the processing time for placing and amending orders. While the processing-time reductions are significant, we don't know exactly what the implications are for the operations in the customer order management process. Furthering exploration of the effects of the Blockchain, our second research question is: 'What are these Blockchain effects on the operations of the customer order management process of FossorCo?'

To answer this question, the simulation of the customer order management process was built in Simul8. Simul8 software was selected because it:

a) is accurate, robust and reliable;

b) requires basic analytical skills to interpret data;

c) is easy to programme for maintaining/updating and enhancing the rule sets to manage griefs;

d) is not astronomically expensive.

These four selection criteria are particularly important for the purposes of capability-building, training and learning-transfer to the participating company's employees. From the IPT theory, the simple information processing plays a key role in securing the sustainability of the Blockchain in the hands of employees.

In developing the simulation on the current-state (without Blockchain) scenario for placing and amending orders, we used four key parameters: (1) the number of new orders by type (scheduled, discrete or EDI) and amended orders; (2) the number of placed and amended orders entering the system; (3) the average time for processing of each order's task; and (4) the average usage of account coordinators.

Using the process maps (Figures 1 and 2) and process specifications from interviews and shadowing, the list of assumptions to simulate scenarios was built. Assumptions include:

1. Availability: account coordinators at 90 per cent efficiency, minus 20 per cent of their time spent on administrative tasks.

2. Batching: orders arrive in batches of approximately equal size.

3. FIFO: orders are dealt with on a first-come, first-served basis.

4. Switching time: two minutes between one order to another.

5. Fungibility: a job can be picked up by any account coordinator.

The scenarios with the Blockchain solution implemented at one year and after five years in operation were simulated (Figure 3), as well as the current-state scenario (without Blockchain) (Figure 4) 


\section{B. Simulation Analysis}

Table VI compares and contrasts the effects on operations in three scenarios: current-state (with no Blockchain) scenario, initial Blockchain state (one year) and mature Blockchain state (five years). The results of the simulation show that there is a 65 per cent reduction in the processing time for placing new orders and a 60 per cent reduction in the processing time for order amends from the current state to the mature Blockchain state.

The average time in the system for processing an order dropped from 515.3 minutes to 22.1 minutes (493.3 minutes saved). Similarly, the average time for amending an order dropped from 380.8 minutes to 132.9 minutes, saving 247.9 minutes.

Instead of the 5.2 (6) account coordinators required in the current (without Blockchain) scenario, the analyses of the Blockchain mature scenario recommend only 2.2. Assuming a similar discrepancy between the real world and the model of 12 per cent, as picked up for the current state, the number increases to 2.7, which can be rounded up to 3 . Hence, there is a 50 per cent reduction in the workload of account coordinators.

The findings of this study show the significant impact of Blockchain on customer order management. It reduces the size of the department by 50 per cent, as well as the processing times for orders by 60 to 65 per cent. 
Sensitivity analysis was carried out in the model and it was demonstrated that the system is robust to deal with variability in the number of orders processed, as well as their interarrival rate. The model is sensitive to the processing time of amending orders (as it would be expected).

\section{TABLE VI}

Simulation results: comparison of Current, Transition (1 yr.) and Mature (5yrs) scenarios of Blockchain in customer order management

\section{Effects of Blockchain on the Customer Order Management-Operations}

In response to our second research question, 'What are the effects of Blockchain in customer order management?', the evaluation of the simulation-based scenarios reveals a reduction in the number of operations. In the placing-an-order process, the current (without the Blockchain) scenario has 21 operations and 20 data storage. The data storage keeps orders waiting to be processed. Conversely, the Blockchain reduced the scenario from 21 operations to 6 operations and from 20 data storage to only 2 . The process for placing a new order is simplified and lean.

Blockchain triggers major reductions in the number of operations and increases their speed. The process for placing a new order, from the moment the customer places the order until the order gets approved and the customer is notified, is analysed under two different scenarios - one without Blockchain, called the 'current scenario', and the other 'with Blockchain scenario'.

1) In the current (without Blockchain) scenario: the process starts with the customer placing an order on the customer interface or on the MRC. Depending on the customer, the order could be an EDI, a scheduled or a discrete order. Each type-follows a different sub-process: (a) EDI processes 4.5 per cent of the total orders coming from only one customer (representing $2 \%$ of total customers); (b) scheduled processes 74 per cent of the total orders coming from 76 per cent of the total customers; (c) and finally, discrete processes 22 per cent of the total orders coming from 22 per cent of the total customers. These orders are managed following one of these sub-processes:

(a) EDI orders: there is an activity question, 'Is there an EDI failure?' If yes, the order goes to grief until the dispute has been resolved; generally, this activity takes 4-8 hours over 2 days. For every 60 orders through EDI, up to 12 failures occur. Once the dispute has been resolved, it continues the normal process until no more actions are required, but the customer does not receive a notification.

(b) Discrete orders: this process starts with the Account Coordinator (AC) manually checking the MRC (the interface for customers to place orders), which generally takes between 5 and 20 minutes. If there is a grief $(60 \%$ of the discrete/scheduled orders have griefs), the AC emails the customer to acknowledge the order (approx. 10 minutes per order). Then the grief is resolved with a series of conference calls that could last 30 minutes per day for up to 5 days. Once the griefs have been resolved or, in the absence of any griefs, there is a five-minute manual task per order for the $\mathrm{AC}$ to input the order into the MFG (a system used to communicate orders and specifications to the manufacturing department).

(c) Scheduled orders: this starts when the AC checks the orders coming to the MRC portal via email (serves 20 customers) or the customer interface (serves 15 customers). Each check takes approximately five minutes. For those customers with MRC updated daily, the AC makes two extra checks per week. Once all the orders have been checked, the AC copies data from the MRC to prepare the input data that will go into the MFG. For discrete and scheduled orders, the account coordinator continues to process the orders by manually recording the orders in the MFG. Once the order has been placed in the MFG, the next action is to ask if customer acknowledgement is required; the majority of times (95\%) the order confirmation is 
formalised in an Excel sheet, which takes approximately one to three hours. Then the order confirmation is sent to the customer by email. In parallel, the MFG orders are stored in the MRG ERP tool.

The analysis of this current (without Blockchain) scenario shows that processing an order continuously requires manual work/input from the $\mathrm{AC}$, particularly in checking the order status, dealing with griefs and copying data from one system to another, or even to an Excel sheet. In addition, the process is extended by the numerous storage points. These recurring checks, multiple manual inputs and duplications of data explain why an order spends a long time in the system. As the simulation shows, the average time of an order in the system is 515.3 minutes.

2) In the Blockchain scenario: the process starts with the customer placing the order in the customer interface (portal), and the entry interface automatically uploads the order in Blockchain. The following step questions whether the order contains a grief (e.g. missing data, incorrect data, unique requirement). If there is grief, a conference call is performed, and as a result of the call the dispute is resolved and finally the order is approved and stored in Blockchain. If there is no grief, the order is approved directly and stored in Blockchain.

The analysis of the Blockchain scenario shows that, as a result of the set of rules programmed in the Blockchain for processing orders, the responses are faster, and therefore the average time of an order in the system is reduced from 515.3 to 22.1 minutes.

This study shows that the Blockchain automatically processes the orders through a series of advanced rules already predefined and set in the Blockchain program. The more advanced the rules are, the more griefs are automatically dealt with by the Blockchain, and consequently the less time an order spends in the system. Finally, customers receive a notification of the order recorded, 'including the order's traceable history'. Occasionally, griefs with unique customer requirements will need to be solved by the AC and then automatically accepted into the Blockchain.

The Blockchain dynamically incorporates new learning 'capability' - from the solutions provided to new griefs - into the set of rules, which makes the Blockchain smarter and more customised, and consequently faster in its response time.

By comparing the simulations between the current and the Blockchain scenarios, the effects of Blockchain on customer order management show an overall increase in operational efficiency in the customer order management processes by:

- Reducing the number of operations needed to place or amend orders, consequently making the customer order management process simpler and leaner: Blockchain reduced the process for placing orders from 21 to 6 operations.

- Reducing the average time of orders in the system: 493.3 minutes were saved for placing orders.

- Showing the traceability of orders through the user interface via dashboards.

- Improving visibility to various supply chain participants through the written rights set on Blockchain.

- Consolidating a single point of entry for placing and amending orders.

- Removing the multiple checkpoints such as MRC, EDI, customer portal and emails.

- Reducing manual input into the orders.

- Eliminating duplications of report status such as Excel sheets.

- Decreasing the number of storage points.

- Reducing the workload of account coordinators by 50 per cent: 3 instead of 6 ACs were required.

- Reducing the quantity of griefs.

- Enhancing the set of advanced rules for processing griefs. Continuous improvements in the set rules, maximising the active utilisation of new learning and therefore making the Blockchain operations more sustainable in future. 


\section{VII.CONCLUSIONS}

This paper has investigated the effect of Blockchain in the customer order management process of a supply chain. There is an emerging, fast-growing body of literature on Blockchain. The growing interest in Blockchain calls for more research, particularly on finances, cryptocurrencies and smart contracts (Avital et al., 2016; Risius and Spohrer, 2017; Nowinski and Kozma, 2017). McLannahan (2016) highlights the need to further understand the feasibility and benefits of this digital technology. This research demonstrates the effects of Blockchain on the efficiency gains, human-processing savings and major reductions in the number and speed of operations in the customer order management process.

Kim and Laskowski (2017), Brennan et al. (2015) and Carter and Koh (2018) argue that there is a need for Blockchain applications in the supply chain with a particular focus on traceability and source tracking. This research provides a detailed description of Blockchain implementation in an industrial supply chain context. The main benefits of a distributed ledger technology are traceability, visibility and security transactions (Palfreyman, 2016; Carter and Koh, 2018). This study contributes to the supply chain literature by demonstrating, from the technology and information systems' perspective, how traceability, visibility and security of transactions are designed and implemented. It demonstrates the selection of front-end to back-end technologies for programming the Blockchain, in addition to the interface used to display the traceability of orders and manage the visibility rights.

\subsection{Theoretical contributions}

First, this study observed that in order to avoid failure in the gathering and managing of customer orders, the company currently relay on the manual input, duplication of data and multiple check points. This observation is important because of the focuses on the resource-based view theory particularly on the capabilities, resources and skills (Barney 1991). The RBV theory applied to Blockchain reflects on the importance of setting the required resources and capacity that underpin an implementation and use of this digital technology. We demonstrated that the RBV provides a theoretical foundation to understand the required re-adaption of current capabilities in pursue of a better competitive position (Carter and Koh, 2018). Blockchain fundamentally changes the way people operate by emigrating from core manual capabilities to new core capabilities - e.g. data analytics, ruleset programming.

This research contributes to RBV theory (Barney, 1991) by demonstrating two RBV competitive valuable capabilities that an organisation develops when implementing and using Blockchain in a supply-demand process such as, the customer order management process (see Table IV). These two RBV competitive valuable capabilities - rare, valuable, inimitable, non-substitutable - are: (1) 'The Blockchain logic and routines that identify and filter competitive opportunities based on customers consumption behaviours and supply chain flexibility knowledge'. (2) 'The Rules' transformation process based on emerging customers' demands by restructuring and integrating existing rules, and building new ones', which make the process highly customised to a particular company and its customers'.

This study also contributes to the dynamic capability theory (Teece, 2007) by demonstrating a new dynamic capability - The Dynamic adaptation of rules and routines by active utilization of new/old learnings based on the evolution of customer demands. This is based on the two RBV competitive valuable capabilities and it leads to the evolution of more sophisticated rules and Blockchain subroutines.

In this way, the framework presented in Table IV proposes which resources are needed for a blockchain implementation, how they can be combined (bundled) to create RVIN (Logic and routines) resources and results in the dynamic capability.

This research demonstrates through the simulation analyses that these two new RBV competitive valuable capabilities and the new dynamic capability maximise the resource efficiency of 'Blockchain customer order management operations' (Barney 1991; Koh, Morris, Ebrahim and Obayi, 2016). These efficiency improvements include: a reduction in the processing time for placing orders by $65 \%$, a reduction for 
amending orders by $60 \%$ from the current state to the mature Blockchain state and human processing savings by around $50 \%$.

Second, this research argues that the two RBV competitive valuable capabilities identified in this research contribute to the Information Processing Theory (IPT) particularly, to the information processing 'analytics capability' by contextualizing the nature of the analytics in the intersection between Blockchain and supply chain processes. The first RBV competitive capability, 'The Blockchain logic and routines' is in principle the 'Blockchain' analytics capability'. This identify and filter competitive opportunities based on customers consumption behaviours and supply chain flexibility knowledge. The second RBV capability 'The Rules' transformation process' is the 'Organization's analytics capability'. It is based on emerging customers' demands by restructuring and integrating existing rules, and building new ones. Both the Blockchain and the organisation analytics capabilities are continuously improved and evolve though three learning mechanisms - experience accumulation, knowledge articulation and knowledge codification process (Zollo and Winter, 2002).

From the information processing theory (IPT) angle, Saberi et al (2018) call for more studies to understand how supply chain processes are affected by the implementation of Blockchain technology. The analytics are critical capabilities to maximise the utilisation and integration of resources in supply-demand processes (Flynn, Hou and Zhao, 2010). Swan (2017) highlights that Blockchain implementation increases information-sharing among supply chain partners. Srinivasan and Swink (2017) and Zhu et al. (2018) suggest that higher levels of supply chain transparency and visibility require a stronger analytics capability. Blockchain provides significant visibility. Finally, regarding resource efficiency, the efficient use of data from the Blockchain demonstrates faster and cheaper, more efficient and reliable traceable operations.

Third, this research contributes to the supply chain theory by taking the Blockchain principles - largely applied in the financial context (e.g. cryptocurrencies and Bitcoin) - and applying them to understand how they apply to operations and management processes, particularly in customer order management.

\subsection{Managerial Implications}

As can be seen from the blockchain implementation and the simulation analysis, this research has illustrated the path to blockchain implementation for the customer order management process. This paper provides clear guidelines for managers to implement blockchain in COM. The fact that the system was developed in-house, and at a relatively low cost, shows managers that they can pilot the introduction of Blockchain to their processes without committing to large investments. The framework presented in Table IV guides managers to identify the resources needed and how to combine them to achieve a successful Blockchain implementation. Although the process tested in this case was the Customer Order Management process, we argue that the approach can be extended to other supply chain processes (e.g. product development, order fulfilment, delivery) since they form part of the extended supply chain processes and there is interaction between the activities of these processes and the COM process.

Based on the dynamic fast-learning environment enabled by the blockchain, there is much that management can do. As Teece (2007) suggests, 'firms need to simultaneously design processes and structures to support the re-adaptation, innovation and transformation of business processes and structures designed for an earlier period', particularly to accommodate the new learning from changing customer consumption behaviours in an increasingly digital era. Using the blockchain platform and previous customer consumption behaviour analyses, managers could set advanced customised rules in the customer order management routines to provide faster responses to customers

\subsection{Limitations}

This research is based on a single in-depth case that has the scope to be tested in future in different contexts. However, we argue that the results are generalisable to other processes in the supply chain since some of the activities will be common across processes (raising, amending and processing orders) Future research needs to confirm this by studying the impact of Blockchain visibility on different supply chain processes and actors - including customers and OEM, providers and others. 


\section{REFERENCES}

Aaron (2018), "6 successful real-life examples of Blockchain technology being implemented", available at: https://e27.co/6-reallife-examples-blockchain-technology-implemented-20180321/ (accessed 30 January 2019).

Aitken, R. (2017), “IBM \& Walmart Launching Blockchain Food Safety Alliance In China With Fortune 500's JD.com”, available at: https://www.forbes.com/sites/rogeraitken/2017/12/14/ibm-walmart-launching-blockchain-food-safety-alliance-in-chinawith-fortune-500s-jd-com/\#38e8f7da7d9c (accessed 30 January 2019)

Alharby, M. and Moorsel, A. van. (2017), "Blockchain Based Smart Contracts : A Systematic Mapping Study", Proceedings of 4th International Conference on Computer Science and Information Technology, AIRCC Publishing Corporation, pp. 125140.

Aranda, D. (2017), "Don't believe all the hype 2: The limitations of the Bitcoin Blockchain", available at: https://ripple.com/insights/dont-believe-all-the-hype-2-the-limitations-of-the-bitcoin-blockchain/ (accessed 30 January 2019).

Avital, M., King, J.L., Beck, R., Rossi, M. and Teigland, R. (2016), "Jumping on the Blockchain Bandwagon: Lessons of the Past and Outlook to the Future", Proceedings of 37th International Conference on Information Systems, Dublin, pp. 1-6.

Besnainou, J. (2017), "Blockchain and Supply Chain Financing: A Conversation with Skuchain", available at: https://www.cleantech.com/blockchain-and-supply-chain-financing-a-conversation-with-skuchain/ (accessed 30 Jan. 2019)

Bext360 (2017), "Traceability and Authenticity", available at: https://www.bext360.com/ (accessed 30 January 2019)

Bocovich, C., Doucette, J.A. and Goldberg, I. (2017), "Lavinia: An audit-payment protocol for censorship-resistant storage", Financial Cryptography and Data Security, Springer, Cham, pp. 601-620.

Brown, R. (2018), "The Corda Platform: An Introduction", available at: https://www.corda.net/content/corda-platformwhitepaper.pdf (accessed 30 January 2019)

Brennan, L., Ferdows, K., Godsell, J., Golini, R., Keegan, R., Kinkel, S., Srai S.J., and Taylor, M. (2015). Manufacturing in the world: where next? International Journal of Operations \& Production Management, 35(9), 1253-1274.

Bunger, M. (2017). Blockchain for industrial enterprises: Hype, reality, obstacles and outlook. Retrieved June 10, 2018, from Davis, L., Dehning, B., \& Stratopoulos, T. (2003). Does the market recognize IT-enabled competitive ad-vantage? Information \& Management, 40(7), 705-716

Carson B., Romanelli G., Walsh P. and Zhumaev A. (2018), "Blockchain beyond the hype: What is the strategic business value?", available at: https://cybersolace.co.uk/CySol/wp-content/uploads/2018/06/McKinsey-paper-about-Blockchain-Myths.pdf (accessed 30 January 2019)

Carter, C., and Koh, L. (2018), “Blockchain disruption on transport: Are you decentralised yet?”, available at: https://s3-eu-west1.amazonaws.com/media.ts.catapult/wp-content/uploads/2018/06/06105742/Blockchain-Disruption-in-Transport-ConceptPaper.pdf (accessed 30 January 2019)

Centers for Disease Control and Prevention (2018), "Outbreak of Multidrug-Resistant Salmonella Infections Linked to Raw Chicken Products", available at: https://www.cdc.gov/salmonella/infantis-10-18/index.html (accessed 30 January 2019)

Conoscenti, M., Vetro, A. and De Martin, J.C. (2017), "Blockchain for the Internet of Things: A systematic literature review", Proceedings of IEEE/ACS International Conference on Computer Systems and Applications, AICCSA, pp. 1-6.

Davis, J. P., Eisenhardt, K. M., \& Bingham, C. B. (2007). Developing theory through simulation methods. Academy of Management. The Academy of Management Review, 32(2): 480-499. Retrieved from https://ezp.lib.cam.ac.uk/login?url=https://search.proquest.com/docview/210972345?accountid=985

Davidson, S., De Filippi, P. and Potts, J. (2016), "Economics of Blockchain”, available at: https://ssrn.com/abstract=2744751 (accessed 30 January 2019).

Dingsøyr, T., Nerur, S., Balijepally, V. and Moe, N.B. (2012), "A decade of agile methodologies: Towards explaining agile software development”, Journal of Systems and Software, Vol. 85 No. 6, pp. 1213-1221.

Dong, F., Zhou, P., Liu, Z., Shen, D., Xu, Z. and Luo, J. (2017), “Towards a fast and secure design for enterprise-oriented cloud storage systems", Concurrency and Computation: Practice and Experience, Vol. 29 No. 19, p. e4177.

Edmondson, A.C. and McManus, S.E. (2007), "Methodological fit in management field research", Academy of Management Review, Vol. 32 No. 4, pp. 1246-1264.

Eisenhardt, K. M. (1989). Building theories from case study research. Academy of Management. 14(4), 532. Retrieved from https://ezp.lib.cam.ac.uk/login?url=https://search.proquest.com/docview/210938650?accountid=9851

Eklab, A., Azaria, A., Halamka, J., \& Lippman, A. (2016), "Case Study for Blockchain in Healthcare: "MedRec" prototype for electronic health records and medical research data", available at: https://www.healthit.gov/sites/default/files/5-56onc_Blockchainchallenge_mitwhitepaper.pdf (accessed 30 January 2019)

Enigma MPC (2018), “Overview Catalyst 0.5.2.”, available at: https://enigma.co/catalyst/ (accessed 30 January 2019)

Everledger (n.d.). Welcome to the digital vault of the future. Retrieved June 23, 2018, from www.everledger.io/

Flynn, B. B., B. Huo, and X. Zhao. 2010. "The Impact of Supply Chain Integration on Performance: A Contingency and Configuration Approach.” Journal of Operations Management 28 (1): 58-71.

Gao, Z., Xu, L., Chen, L., Zhao, X., Lu, Y. and Shi, W. (2018), “Coc: A unified distributed ledger based supply chain management 
system", Journal of Computer Science and Technology, Vol. 33 No. 2, pp. 237-248.

Gehman, Glaser, Eisenhardt, Gioia, Langley, and Corley,"Finding Theory-Method Fit: A Comparison of Three Qualitative Approaches to Theory Building." Journal of Management Inquiry. 27.3 (2018): 284-300.

Glaser, F. (2015), "Beyond Cryptocurrencies - A Taxonomy of Decentralized Consensus Systems", 23rd European Conference on Information Systems (ECIS), Munster.

Glaser, F. (2017), "Pervasive decentralisation of digital infrastructures: a framework for blockchain enabled system and use case analysis", Proceedings of the 50th Hawaii International Conference on System Sciences, Waikoloa, pp. 1543-1552.

Government Office for Science (2016), "Distributed Ledger Technology: Beyond block chain", available at: https://assets.publishing.service.gov.uk/government/uploads/system/uploads/attachment_data/file/492972/gs-16-1distributed-ledger-technology.pdf (accessed 30 January 2019)

Hackius, N. and Petersen, M. (2017), "Blockchain in logistics and supply chain: trick or treat?", Proceedings of the Hamburg International Conference of Logistics (HICL), epubli, pp. 3-18.

Holotiuk, F., Pisani, F. and Moormann, J. (2017), "The Impact of Blockchain Technology on Business Models in the Payments Industry", Proceedings of 13th International Conference on Wirtschaftsinformatik, St. Gallen, pp. 912-926.

Johnson, E. (2016), "Special Coverage: A Blockchain-backed bill of lading", available at: https://www.americanshipper.com/main/news/special-coverage-a-Blockchainbacked-bill-of-lading-66056.aspx (accessed 30 January 2019)

Karafiloski, E. and Mishev, A. (2017), "Blockchain solutions for big data challenges: A literature review", Proceedings of the 17th IEEE International Conference on Smart Technologies, IEEE, Ohrid, pp. 763-768.

Ketokivi, M., \& Choi, T. (2014). Renaissance of case research as a scientific method. Journal of Operations Management, 32(5), 232. Retrieved from https://ezp.lib.cam.ac.uk/login?url=https://search.proquest.com/docview/1539349084?accountid=9851

Kim, H.M. and Laskowski, M. (2018), "Toward an ontology-driven blockchain design for supply-chain provenance", Intelligent Systems in Accounting, Finance and Management, Vol. 25 No. 1, pp. 18-27.

Koetsier, J. (2017), "Blockchain Beyond Bitcoin: How Blockchain Will Transform Business in 3 to 5 Years", available at: https://www.inc.com/john-koetsier/how-Blockchain-will-transform-business-in-3-to-5-years.html (accessed 30 January 2019)

Koh, S.C.L., Morris, J., Ebrahimi, S.M. and Obayi, R. (2016), "Integrated resource efficiency: measurement and management", International Journal of Operations \& Production Management, Vol. 36 No. 11, pp. 1576-1600.

Kshetri, N. (2018), "1 Blockchain's roles in meeting key supply chain management objectives", International Journal of Information Management, Vol. 39, pp. 80-89.

Lamming, R., Orzes, G., Nassimbeni, G., Jia, F. and Sartor, M. (2015), "International purchasing offices in China: roles and resource/capability requirements”, International Journal of Operations \& Production Management, Vol. 35 No. 8, pp. 11251157.

Levin, H.M. and McEwan, P.J. (2001), Cost-Effectiveness Analysis: Methods and Applications, Sage publications, Thousand Oaks, CA.

Maurer, B. 2017, "Blockchains Are a Diamond's Best Friend: Zelizer for the Bitcoinmoment”, in Bandelj, N., Wherry, F. and Zelizer V. (Eds.) Money Talks: Explaining How Money Really Works, Princeton, Princeton University Press, pp. 215-230.

McConaghy, T. and Holtzman, D. (2015), "Towards An Ownership Layer for the Internet", available at: https://assets.ctfassets.net/sdlntm3tthp6/resource-asset-r391/d110e1250fe31959150659144c424feb/5d5f7fde-646f-4b1c8fe8-e939080348a0.pdf (accessed 30 January 2019)

Mendling, J., Weber, I., Aalst, W. Van Der, Brocke, J. Vom, Cabanillas, C., Daniel, F., Debois, S., et al. (2018), "Blockchains for business process management-challenges and opportunities", ACM Transactions on Management Information Systems (TMIS), ACM, Vol. 9 No. 1, pp. 1-16.

Miau, S. and Yang, J.-M. (2018), "Bibliometrics-based evaluation of the Blockchain research trend: 2008-March 2017", Technology Analysis \& Strategic Management, Vol. 30 No. 9, pp. 1029-1045.

Naudin, I. V. (2017), “TransActiv Grid, smart energy made in Brooklyn”, available at: https://medium.com/le-lab/transactiv-gridsmart-energy-made-in-brooklyn-6fa55f770b6a (accessed 30 January 2019)

Naumoff, A. (2016), "Engine for Blockchain: Toyota Financial Services joins R3", available at: https://cointelegraph.com/news/engine-for-Blockchain-toyota-financial-services-joins-r3 (accessed 30 January 2019)

Palfreyman, J. (2016), "Blockchain for Asset Registration", available at: https://www.ibm.com/blogs/insights-onbusiness/government/Blockchain-asset-registration/ (accessed 30 January 2019)

Popper, N. and Lohr, S. (2017), "Blockchain: A Better Way to Track Pork Chops, Bonds, Bad Peanut Butter?", available at: https://www.nytimes.com/2017/03/04/business/dealbook/Blockchain-ibm-bitcoin.html (accessed 30 January 2019)

Powerledger, A. (2017), "Press Release", available at: https://web.powerledger.io/mediarelease (accessed 30 January 2019)

Project Provenance Ltd. (2016), "From shore to plate: Tracking tuna on the Blockchain", available at: https://www.provenance.org/tracking-tuna-on-the-Blockchain (accessed 30 January 2019)

Ripeanu, M. (2001), "Peer-to-peer architecture case study: Gnutella network", Proceedings of the 1st International Conference on Peer-to-Peer Computing, IEEE, Linkoping, pp. 99-100.

Risius, M. and Spohrer, K. (2017), “A Blockchain Research Framework”, Business \& Information Systems Engineering, Vol. 59 No. 6, pp. 385-409. 
Rotunno, R., Cesarotti, V., Bellman, A., Introna, V. and Benedetti, M. (2014), "Impact of track and trace integration on pharmaceutical production systems", International Journal of Engineering Business Management, Vol. 6 No. 25.

Saberi, S., Kouhizadeh, M., Sarkis, J. and Shen, L. (2018), "Blockchain technology and its relationships to sustainable supply chain management", International Journal of Production Research, Taylor \& Francis, pp. 1-19.

Scopus (2018) Retrieved July 22, 2018, from https://www.scopus.com

Seebacher, S. and Schüritz, R. (2017), "Blockchain technology as an enabler of service systems: A structured literature review", Proceeding of the 8th International Conference on Exploring Services Science, Springer, Cham, pp. 12-23.

Shieber, J. (2017), "Toyota pushes into Blockchain tech to enable the next generation of cars", available at: https://techcrunch.com/2017/05/22/toyota-pushes-into-blockchain-tech-to-enable-the-next-generation-of-cars/ (accessed 30 January 2019)

Shin, L. (2017), "Looking To Integrate Blockchain Into Your Business? Here's How", available at: https://www.forbes.com/sites/laurashin/2016/05/10/looking-to-integrate-Blockchain-into-your-business-hereshow/\#74328f7ala15 (accessed 30 January 2019)

Skuchain (2018), "Empower my supply chain", available at: http://www.skuchain.com/ (accessed 30 January 2019)

Steiner J. and Baker J. (2015), "Blockchain: the solution for transparency in product supply chain", available at: https://www.provenance.org/whitepaper (accessed 30 January 2019)

Sun, J., Yan, J. and Zhang, K.Z.K. (2016), "Blockchain-based sharing services: What blockchain technology can contribute to smart cities", Financial Innovation, Vol. 2 No. 1, pp. 1-9.

Swan, M. and de Filippi, P. (2017), "Toward a Philosophy of Blockchain: A Symposium: Introduction", Metaphilosophy, Vol. 48 No. 5, pp. 603-619.

Tapscott, D., \& Tapscott, A. (2017). How blockchain will change organizations. MIT Sloan Management Review, 58(2), 10-13.

Team Ripple (n.d.), "Ripple Reports Positive Results From xRapid Pilots", available at: https://ripple.com/ripple_press/ripplereports-positive-results-xrapid-pilots/ (accessed 30 January 2019)

Vorabutra, J. (2016), "Why Blockchain is a Game Changer for Supply Chain Management Transparency" available at: http://www.supplychain247.com/article/why_Blockchain_is_a_game_changer_for_the_supply_chain (accessed 30 Jan. 2019)

Vorick, D., \& Champine, L. (2014, November 29). Sia. Retrieved June 23, 2018, from https://sia.tech/[IR1]

Vu, K. (2018), "Bext360 and Coda Coffee Release The World's First Blockchain-traced Coffee from Bean to Cup", available at: https://www.econotimes.com/bext360-and-Coda-Coffee-Release-The-Worlds-First-Blockchain-traced-Coffee-from-Beanto-Cup-1256337 (accessed 30 January 2019)

Weick, K. E. (1989). Theory Construction as Disciplined Imagination. Academy of Management Review. 14,(4): 516-531. www.jstor.org/stable/258556 DOI: 10.2307/258556

Welsh I and Lyons CM (2001) Evidence-based care and the case for intuition and tacit knowledge in clinical assessment and decision making in mental health nursing practice: an empirical contribution to the debate. Journal of Psychiatric \& Mental Health Nursing. 8(4):299-305

World Economic Forum (2015), "Deep shift: Technology tipping points and societal impact", available at: http://www3.weforum.org/docs/WEF_GAC15_Technological_Tipping_Points_report_2015.pdf (accessed 30 Jan. 2019)

Xu, L. Da, Xu, E.L. and Li, L. (2018), "Industry 4.0: state of the art and future trends", International Journal of Production Research, Vol. 56 No. 8, pp. 2941-2962.

Yermack, D. (2017), “Corporate governance and blockchains", Review of Finance, Vol. 21 No. 1, pp. 7-31.

Yin, R.K. (2009), Case Study Research : Design and Methods, Sage publications, Thousand Oaks, CA.

Yli-Huumo, J., Ko, D., Choi, S., Park, S. and Smolander, K. (2016), "Where Is Current Research on Blockchain Technology?-A Systematic Review", PLOS ONE, Vol. 11 No. 10, pp. 1-27.

Zollo, M., \& Winter, S. G. (2002). Deliberate learning and the evolution of dynamic capabilities. Organization Science, 13(3): 339351. Retrieved from https://ezp.lib.cam.ac.uk/login?url=https://search.proquest.com/docview/213833893?accountid=9851

Zyskind, G., Nathan, O., \& Pentland, A. (n.d.), "Decentralizing Privacy: Using Blockchain to Protect Personal Data", available at: https://enigma.co/ZNP15.pdf (accessed 30 January 2019) 


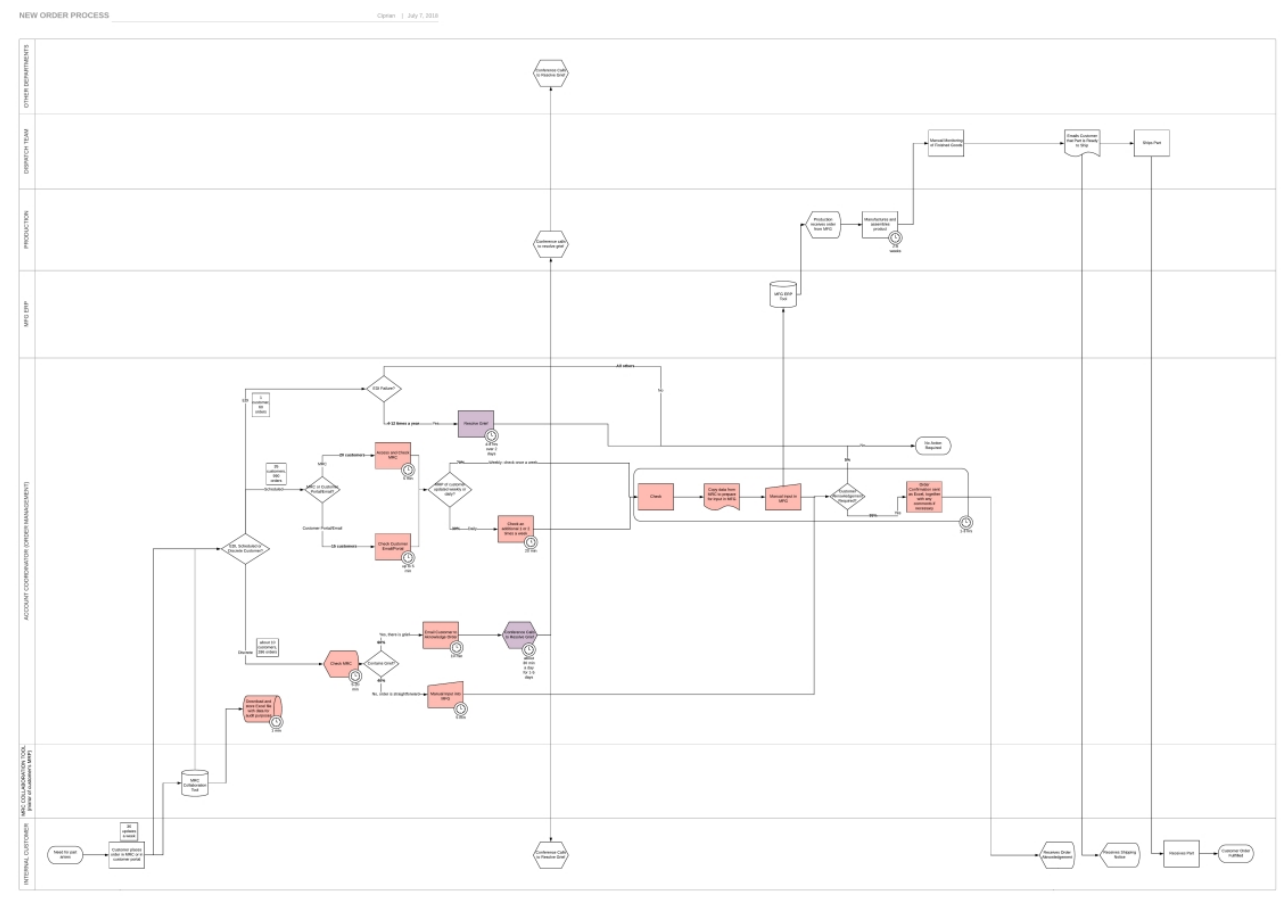

Figure 1 Current Place Order Process Map 


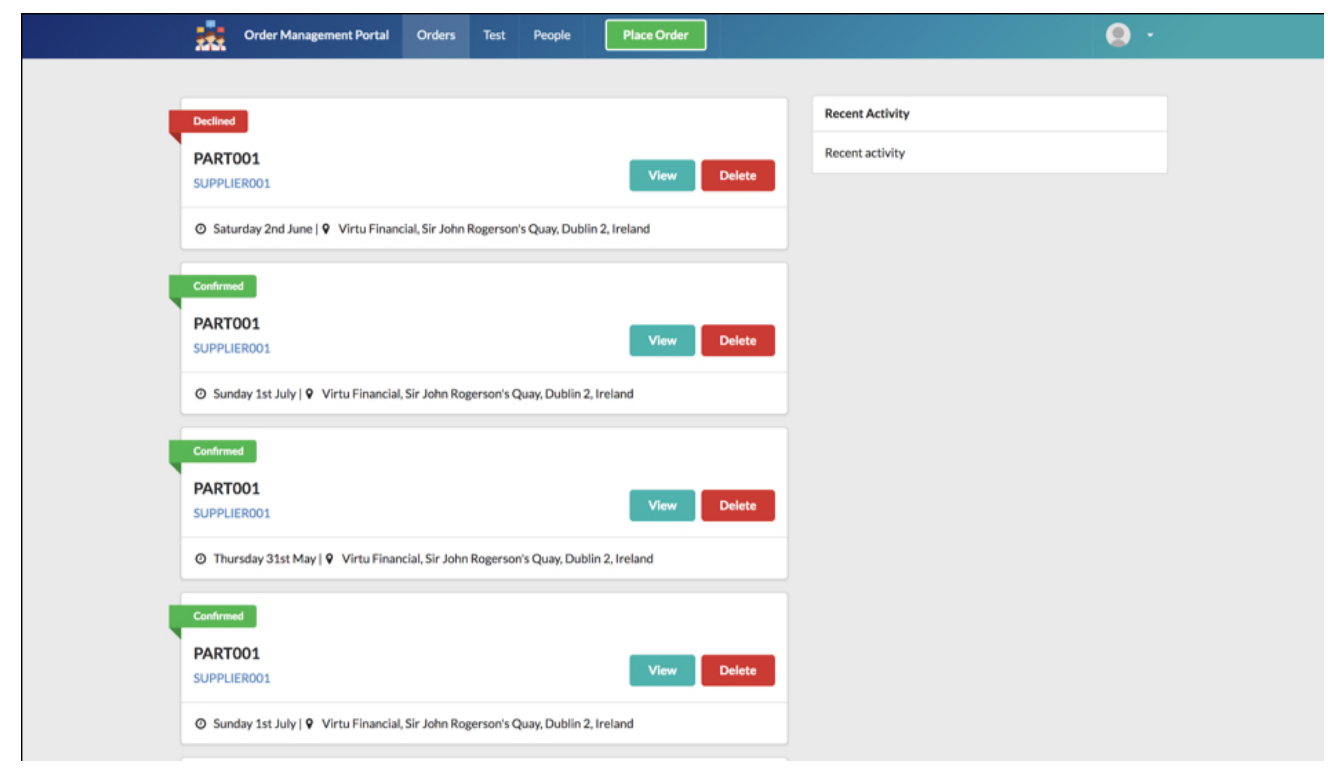

Figure 2. Place order dashboard 


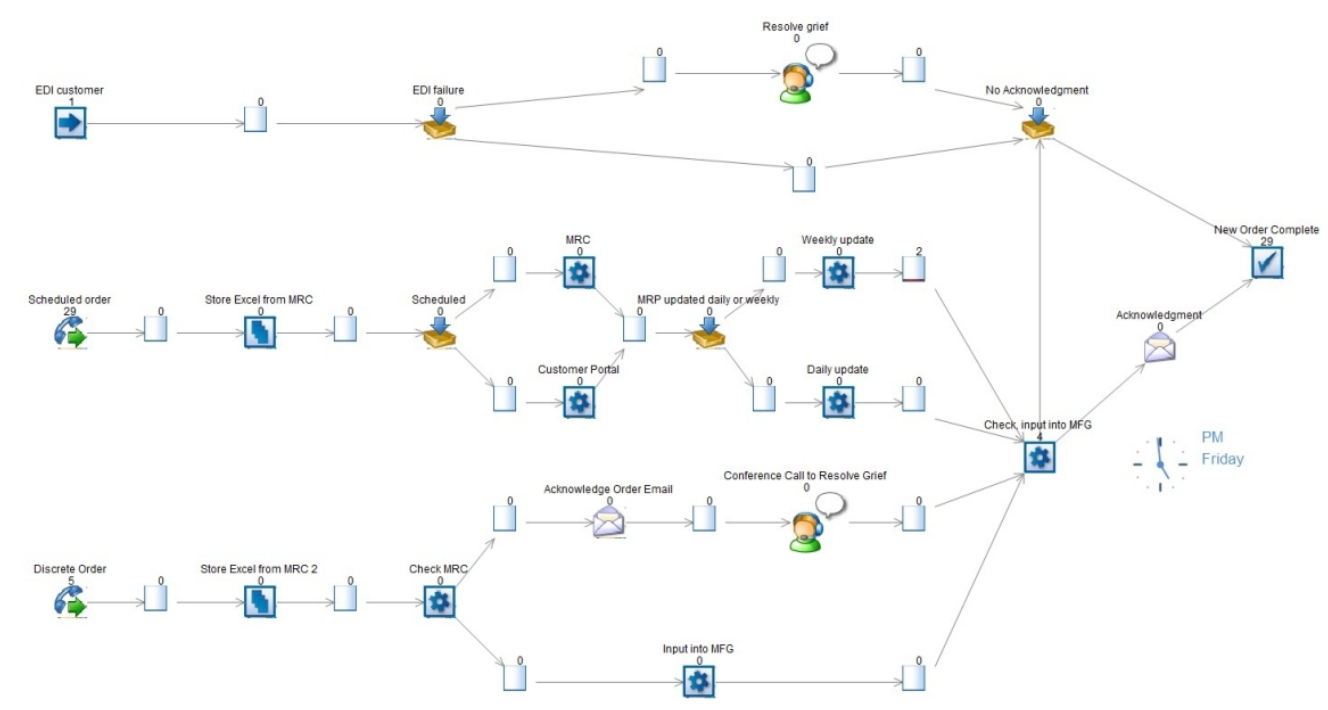

Figure 3. Simulation current stage for placing orders

$304 \times 159 \mathrm{~mm}(120 \times 120 \mathrm{DPI})$ 


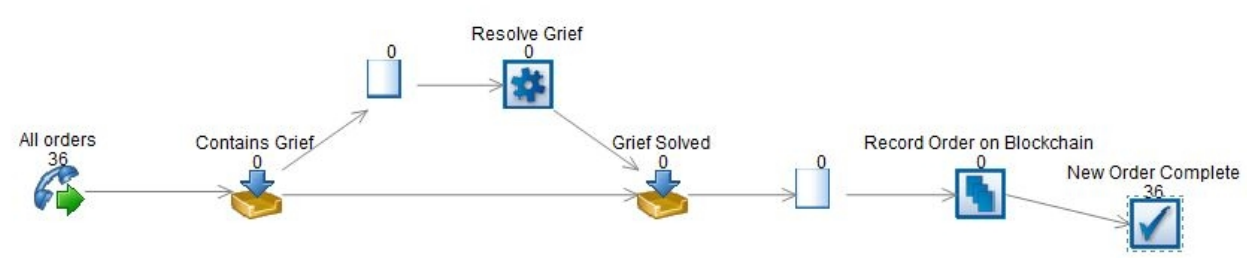

Figure 4. Simulation Blockchain stage for placing orders $184 \times 79 \mathrm{~mm}(120 \times 120$ DPI $)$ 


\begin{tabular}{|c|c|c|c|c|}
\hline Case & Industry & Use of Blockchain within Supply Chain Processes & Level of Implementation & Results and Benefits Achieved \\
\hline $\begin{array}{l}\text { Agri-food } \\
\text { supply } \\
\text { chain } \\
\text { system } \\
\text { (Feng, 2016) }\end{array}$ & Food & $\begin{array}{l}\text { Blockchain implemented in the full supply chain, from } \\
\text { growing, production, processing and distribution, to } \\
\text { warehousing and retail. Blockchain and RFID } \\
\text { technologies applied to an agricultural supply chain to } \\
\text { track food from 'farm to fork'. Blockchain oversees the } \\
\text { quality, safety and transport conditions of food products at } \\
\text { all stages of production. }\end{array}$ & Conceptual. & No results proved yet. \\
\hline $\begin{array}{l}\text { Walmart } \\
\text { and IBM } \\
\text { 'Food } \\
\text { Trust' } \\
\text { (Aitken, } \\
2017 \text { ) }\end{array}$ & Food & $\begin{array}{l}\text { Blockchain implemented in the full supply chain, from } \\
\text { growing, production, processing and distribution, to } \\
\text { warehousing and retail. Blockchain improves food safety, } \\
\text { as contaminated food can be tracked to find its origin and } \\
\text { path in order to remove products from sales and } \\
\text { distribution and stop further spread. }\end{array}$ & $\begin{array}{l}\text { Pilot (August 2017). } \\
\text { Tracking products from } \\
\text { South America to retailers } \\
\text { in the US. Also piloted } \\
\text { from a Chinese farm to a } \\
\text { Chinese retailer (Popper \& } \\
\text { Lohr, 2017). }\end{array}$ & $\begin{array}{l}\text { From first pilot, numerous important } \\
\text { pieces of information such as } \\
\text { expiration date of produce, shipping } \\
\text { details, farm of origin were recorded on } \\
\text { the blockchain and immediately made } \\
\text { available to interested parties (Hackius } \\
\text { and Petersen, 2017). }\end{array}$ \\
\hline $\begin{array}{l}\text { Bext360 } \\
(\mathrm{Bext360} \\
2017)\end{array}$ & Food & $\begin{array}{l}\text { Blockchain applied in the complete supply chain, from } \\
\text { growing, production, processing, distribution and } \\
\text { warehousing to retail. The software-as-a-service platform } \\
\text { aims to increase the supply chain transparency of goods } \\
\text { from producer to consumer to validate whether the raw } \\
\text { material was correctly labelled, ethically sourced and the } \\
\text { parties supported by the purchase. }\end{array}$ & $\begin{array}{l}\text { Proof-of-concept } \\
\text { demonstrated in November } \\
2017 \text { by tracking coffee } \\
\text { supply chain from crops in } \\
\text { Uganda to retail shops in } \\
\text { Colorado, US. }\end{array}$ & $\begin{array}{l}\text { Benefits include: end-customers had } \\
\text { the visibility of the location of the } \\
\text { harvest, famers' identification, quality } \\
\text { rating of beans, pay-outs at every stage } \\
\text { of the handover and the identity of } \\
\text { purchasers }(\mathrm{Vu}, 2018) \text {. }\end{array}$ \\
\hline $\begin{array}{l}\text { Skuchain } \\
\text { (Skuchain, } \\
\text { 2018) }\end{array}$ & Goods & $\begin{array}{l}\text { Blockchain applied to the inventory procurement and } \\
\text { inventory finances of shipped goods across countries. } \\
\text { Blockchain and smart contracts are implemented to } \\
\text { increase information-sharing and control in inventory } \\
\text { procurement for the participants to the supply chain } \\
\text { without compromising the privacy of sensitive data. }\end{array}$ & $\begin{array}{l}\text { Pilot (2016). Cotton } \\
\text { shipment from Houston to } \\
\text { China in a CMA CGM } \\
\text { ship. This first used-case } \\
\text { was concerned with } \\
\text { Blockchain digitisation of } \\
\text { the inventory finance } \\
\text { (Johnson, 2016). }\end{array}$ & $\begin{array}{l}\text { Suppliers obtained working capital } \\
\text { relief by not having to take on } \\
\text { expensive financing. Buyers obtained a } \\
\text { lower cost of goods in addition to } \\
\text { holding inventory off the books for } \\
\text { longer. Improved transparency } \\
\text { considering the trade's agreement } \\
\text { terms (Besnainou, 2017). }\end{array}$ \\
\hline $\begin{array}{l}\text { Maersk and } \\
\text { IBM } \\
\text { (Popper and } \\
\text { Lohr, 2017) }\end{array}$ & $\begin{array}{l}\text { Perishables } \\
\text { Logistics }\end{array}$ & $\begin{array}{l}\text { Blockchain applied in the distribution and shipment } \\
\text { across continents involving border, customs and port } \\
\text { authorities. Blockchain tracks perishable items as they are } \\
\text { shipped across continents. Multiple agencies participated } \\
\text { in the projects, from supply chain partners to border, } \\
\text { customs and port authorities. }\end{array}$ & $\begin{array}{l}\text { Two pilots (2016 and } \\
2017) \text { with the aim of } \\
\text { going into production in } \\
2019 \text { (Hackius and } \\
\text { Petersen, 2017). }\end{array}$ & $\begin{array}{l}\text { Successful pilots: accurate container } \\
\text { tracking and digitising their } \\
\text { information, resulting in potential } \\
\text { significant cost savings when deployed } \\
\text { at full scale. All partners obtained full } \\
\text { visibility into the container status. }\end{array}$ \\
\hline $\begin{array}{l}\text { Modum } \\
\text { (Modum, } \\
\text { 2017) }\end{array}$ & $\begin{array}{l}\text { Health and } \\
\text { Safety } \\
\text { Compliance }\end{array}$ & $\begin{array}{l}\text { Blockchain in supply chain focused on the use of policy } \\
\text { enforcement (use verification and payments of the assets, } \\
\text { emissions when they exceed environmental standards). } \\
\text { Blockchain verifies environmental conditions by placing } \\
\text { sensors around assets in transit, and checks results against } \\
\text { the limits set out in smart contracts, to make sure standards } \\
\text { of health and safety are respected. }\end{array}$ & $\begin{array}{l}\text { First pilot with } 55 \\
\text { shipments. Second pilot } \\
\text { with } 500 \text { shipments. }\end{array}$ & No benefits published. \\
\hline $\begin{array}{l}\text { Everledger } \\
\text { (Everledger, } \\
\text { n.d.) }\end{array}$ & $\begin{array}{l}\text { High-value } \\
\text { Assets } \\
\text { [Diamonds] }\end{array}$ & $\begin{array}{l}\text { Blockchain applied in the complete supply chain, from } \\
\text { mining, processing and distribution to retailing. } \\
\text { Everledger blockchain is a platform designed to track the } \\
\text { provenance of high-value assets - diamonds - using smart } \\
\text { contracts and IoT. It provides supply chain partners with } \\
\text { tamper-proof records of an asset's history, authenticity } \\
\text { and ownership in an attempt to increase transparency and } \\
\text { minimise fraud. }\end{array}$ & $\begin{array}{l}\text { Mature/fully implemented } \\
\text { in the business model. } \\
\text { Since April 2014, } \\
\text { blockchain registry of over } \\
2.2 \text { million diamonds and } \\
\text { adds around 100,000 a } \\
\text { month (Aaron, 2018). }\end{array}$ & $\begin{array}{l}\text { Successful implementation. } \\
\text { Blockchain is an important part of the } \\
\text { business model sold to customers and } \\
\text { end-users. }\end{array}$ \\
\hline $\begin{array}{l}\text { Toyota } \\
\text { Financial } \\
\text { Services } \\
\text { (Naumoff, } \\
2018 \text { ) }\end{array}$ & Automotive & $\begin{array}{l}\text { Blockchain applied to the distribution and finances across } \\
\text { countries. This blockchain tracks the ownership and state } \\
\text { of auto parts as they are being transferred across countries } \\
\text { and factories, as well as helping to prevent and cope with } \\
\text { supply chain disruptions. }\end{array}$ & Conceptual. & N/A \\
\hline
\end{tabular}

\section{TABLE I}

Blockchain applications in supply chain cases 


\section{Blockchain-Driven Customer Order Management}

TABLE II

Research design logic: question and associated methods and techniques

\begin{tabular}{|l|l|l|}
\hline Research Question & Method & Steps and Techniques \\
\hline $\begin{array}{l}\text { 1. How could a blockchain } \\
\text { program be coded with basic in- } \\
\text { house resources and capabilities } \\
\text { (technology/skills)? }\end{array}$ & $\begin{array}{l}\text { Designing and } \\
\text { implementing } \\
\text { blockchain }\end{array}$ & $\begin{array}{l}\text { 1. Map: information flow } \\
\text { 2. Selection: digital technologies } \\
\text { 3. Build: blockchain architecture }\end{array}$ \\
& & $\begin{array}{l}\text { 4. Program: blockchain app for customer order management } \\
\text { 5. Program: user interface }\end{array}$ \\
$\begin{array}{l}\text { 2. What are the effects of the } \\
\text { blockchain on customer order } \\
\text { management operations? }\end{array}$ & Simulation- & $\begin{array}{l}\text { 1. Map current capabilities: including digital and gaps } \\
\text { based approach }\end{array}$ \\
& & $\begin{array}{l}\text { 2. Map the processes } \\
\text { 3. Simulate current scenario and validate it } \\
\text { 4. Build a set of scenarios } \\
\text { 5. Evaluation scenarios: current vs blockchain [@ } 1 \& 5 \text { years] }\end{array}$ \\
\hline
\end{tabular}




\title{
Blockchain-Driven Customer Order Management
}

\author{
TABLE III \\ Blockchain technology selection, architecture and information flow
}

\begin{tabular}{ll}
\hline Phase & Process \\
\hline $\begin{array}{l}\text { 1. Selection of } \\
\text { technologies }\end{array}$ & Back-end technology is concerned with security and \\
& content management. The code is written in a language \\
that can communicate with the server and retrieve the right & \\
information from the database. The private type of & \\
& blockchain - permissioned, closed network blockchain - \\
& is selected on the basis of its perfect fit for the tasks' \\
& context and the simplicity of its use. \\
& Options: (1) from scratch, (2) Hyperledger Fabric, (3) \\
& Hyperledger Fabric + Hyperledger Composer, (4) \\
& Ethereum Virtual Machine.
\end{tabular}

Front-end technology (also called user interface) is concerned with usability, creative output and functional user experience. It communicates with the server by way of a RESTful API. Exposing a RESTful API on the backend side is one of the most appropriate methods for getting the front end to communicate with the back end. Options: (1) Angular, (2) HTML + CSS, (3) React, (4) Vue.js, (5) Electron.

2. Building the architecture

The system architecture has a few components that must communicate seamlessly in order for the full-stack application to work. The opposite figure illustrates how a client application is subscribed to the Fabric runtime. The full-stack blockchain (mobile/Web/API) solution contains the transaction logic that is executed on the Fabric runtime. Hyperledger Composer (SDK) runs on top of Fabric (SDK). Composer develops a 'business network' archive and components and RESTful APIs that interact with customer applications and finally deploy the network to a live instance of a Fabric runtime. This composer offers superior integration capabilities by a LoopBack connector and RESTful API.

3. Designing the
blockchain
information
flow for placing
and amending
orders

The information logic for placing an order starts when the customer communicates with the blockchain by calling the RESTful API. The RESTful API is assisted by the server, and then the browser consumes the API, allowing it to be manipulated. The REST server is able to generate a set of endpoints from the Composer model. The customer interacts with the blockchain by sending an HTTP request to the server via an endpoint that the API supports, which then signals a transaction to be submitted to the blockchain. This transaction executes the logic and verifies that the submitted order meets the rules. If it does, the order is committed to the blockchain, but if it does not, the order is automatically rejected. Either way, the user is notified through a response that is returned to the client application. For amending orders, a similar logic is followed.

\section{Results}

The Hyperledger Composer and Hyperledger

Fabric combination is the most suitable choice for programming our blockchain prototype. This combination is selected because of: (a) its ability to create neat private blockchain networks; (b) the low barrier to entry, unlike the alternatives; and (c) the fast execution: an end-to-end throughput of more than 3,500 transactions per second with latency of less than one second.

React is selected because it is the most suitable interface, and it is widely used in industry for rapid Web applications.

\section{Customer-Blockchain Architecture}

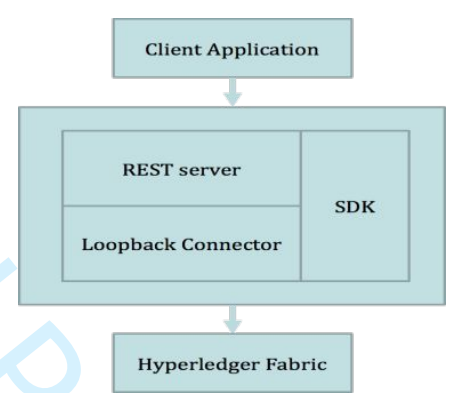

Opening order status 'blockchain visibility' to other parts of the supply chain is realised though the blockchain's RESTful API.

Blockchain information logic for placing an

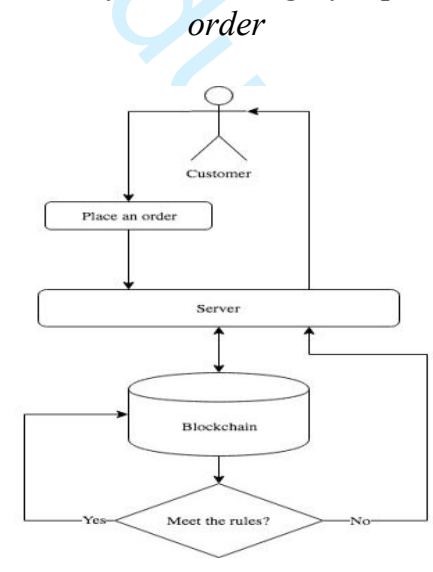




\title{
Blockchain-Driven Customer Order Management
}

\author{
TABLE IV
}

Evolution from resources to dynamic capabilities

\begin{tabular}{|c|c|c|c|}
\hline Resources & $\begin{array}{l}\text { Bundled resources: } \\
\text { Integration }\end{array}$ & $\begin{array}{l}\text { RBV competitive valuable } \\
\text { capabilities: rare, valuable, } \\
\text { inimitable, non-substitutable } \\
\text { [Barney, 1991] }\end{array}$ & $\begin{array}{l}\text { Dynamic } \\
\text { Capabilities: sensing, } \\
\text { sizing, transforming } \\
{[\text { Teece, 2007] }}\end{array}$ \\
\hline $\begin{array}{l}\text { BLOCKCHAIN (BC) } \\
\text { - In-house } \\
\text { Blockchain } \\
\text { programming } \\
\text { skills } \\
\text { - Blockchain } \\
\text { technology: back- } \\
\text { end and front-end } \\
\text { - Tailored } \\
\text { interactive } \\
\text { Blockchain } \\
\text { dashboards }\end{array}$ & $\begin{array}{l}\text { - Blockchain flexible } \\
\text { design: the platform } \\
\text { surrounded by } \\
\text { independent sub- } \\
\text { routines for easy } \\
\text { programming of new } \\
\text { rules or deleting/ } \\
\text { freezing/ unfreezing } \\
\text { existing ones. }\end{array}$ & $\begin{array}{l}\text { - BC logic \& routines that } \\
\text { identify and filter competitive } \\
\text { opportunities based on } \\
\text { customers consumption } \\
\text { behaviours and supply chain } \\
\text { flexibility knowledge. } \\
\text { This is the Blockchain } \\
\text { Analytics Capability }\end{array}$ & $\begin{array}{l}\text { - Dynamic adaptation } \\
\text { of rules and routines } \\
\text { by active utilization of } \\
\text { new/old learnings } \\
\text { based on the evolution } \\
\text { of customer demands } \\
\text { - Dynamic learning. } \\
\text { This leads to the } \\
\text { evolution of more } \\
\text { sophisticated rules } \\
\text { and BC subroutines }\end{array}$ \\
\hline $\begin{array}{l}\text { KNOWLEDGE } \\
\text { - Customer } \\
\text { knowledge } \\
\text { - Account } \\
\text { Coordinators' } \\
\text { experience: } \\
\text { managing orders } \\
\text { - Knowledge of } \\
\text { downstream } \\
\text { supply chain's } \\
\text { flexibility }\end{array}$ & $\begin{array}{l}\text { - Tacit and codified } \\
\text { knowledge of } \\
\text { customers' } \\
\text { consumption } \\
\text { behaviours }\end{array}$ & $\begin{array}{l}\text { - Rules' transformation process } \\
\text { based on emerging customers } \\
\text { demands by restructuring and } \\
\text { integrating existing rules, and } \\
\text { building new ones, which } \\
\rightarrow \text { make the process highly } \\
\text { customised to a particular } \\
\text { company and its customers. } \\
\text { This is the Organization's } \\
\text { Analytics Capability }\end{array}$ & \\
\hline $\begin{array}{l}\text { OTHER RESOURCES } \\
\text { - IT infrastructure } \\
\text { - Data storage } \\
\text { - Account } \\
\text { coordinators } \\
\text { - COM Manager }\end{array}$ & & & \\
\hline
\end{tabular}




\section{Blockchain-Driven Customer Order Management}

TABLE V

Aggregated results of a trial of 12 one-week simulations of the current-state scenario

\begin{tabular}{|c|c|c|c|c|c|c|c|c|c|c|c|c|c|c|c|c|}
\hline Simulation Object & Performance Measure & Run 1 & 2 & 3 & 4 & 5 & 6 & 7 & 8 & 9 & 10 & 11 & 12 & $-95 \%$ & Average & $95 \%$ \\
\hline EDI customer & Number Entered & 1 & 1 & 1 & 1 & 1 & 1 & 1 & 1 & 1 & 1 & 1 & 1 & 1 & 1 & \\
\hline Scheduled order & Number Entered & 25 & 37 & 31 & 27 & 32 & 34 & 33 & 40 & 34 & 35 & 31 & 29 & 29.6881 & 32.3333 & 34.9786 \\
\hline Discrete Order & Number Entered & 7 & 10 & 3 & 6 & 5 & 7 & 8 & 13 & 11 & 6 & 7 & 5 & 5.54989 & 7.33333 & 9.11678 \\
\hline \multirow[t]{5}{*}{ Account Coordinator } & Utilization \% & 114.24 & 112.369 & 107.457 & 104.643 & 110.025 & 107.903 & 115.098 & 112.734 & 108.057 & 113.253 & 109.945 & 110.314 & 108.512 & 110.503 & 100 \\
\hline & Traveling \% & 0.00912 & 0.00711 & 0.00816 & 0.00746 & 0.00868 & 0.00991 & 0.01053 & 0.00912 & 0.00816 & 0.0079 & 0.00816 & 0.00851 & 0.00794 & 0.00857 & 0.00919 \\
\hline & Minimum Use & 0 & 0 & 0 & 0 & 0 & 0 & 0 & 0 & 0 & 0 & 0 & & & & \\
\hline & Average Use & 5.42703 & 5.33817 & 5.10483 & 4.97115 & 5.22683 & 5.12601 & 5.46782 & 5.35552 & 5.13332 & 5.38018 & 5.22302 & 5.24055 & 5.15494 & 5.24954 & 5.34413 \\
\hline & Maximum Use & 6 & 6 & 6 & 6 & 6 & 6 & 6 & 6 & 6 & 6 & 6 & 6 & 6 & 6 & \\
\hline Customer places Amend & Number Entered & 42 & 39 & 32 & 39 & 43 & 34 & 46 & 30 & 47 & 32 & 41 & 43 & 35.3551 & 39 & 42.6449 \\
\hline Significant Amend Done & Number Completed Jobs & 1 & 1 & 0 & 0 & 1 & 0 & 0 & 0 & 0 & 0 & 0 & 0 & 0 & 0.25 & 0.53736 \\
\hline Amend Complete & $\%$ In System Less Than Time Limit & 97.2222 & 76 & 100 & 90.3226 & 100 & 100 & 100 & 100 & 97.0588 & 100 & 96.6667 & 100 & 91.967 & 96.4392 & 100 \\
\hline New Order Complete & $\%$ In System Less Than Time Limit & 100 & 71.4286 & 100 & 96 & 100 & 100 & 97.1429 & 80 & 75 & 100 & 93.3333 & 100 & 85.894 & 92.7421 & 99.5901 \\
\hline \multirow[t]{4}{*}{ Amend Complete } & Minimum Time in System & 20.9198 & 17.3844 & 21.3825 & 18.1285 & 11.2732 & 26.5723 & 26.8438 & 12.8099 & 22.5641 & 64.1644 & 24.0071 & 16.1476 & 14.7993 & 23.5165 & 32.2337 \\
\hline & Average Time in System & 332.472 & 638.561 & 225.523 & 467.964 & 204.504 & 259.426 & 399.048 & 293.287 & 558.27 & 457.451 & 401.495 & 331.549 & 296.305 & 380.796 & 465.286 \\
\hline & Maximum Time in System & 981.844 & 1215.59 & 612.387 & 1306.67 & 766.435 & 546.304 & 884.406 & 659.57 & 1066.11 & 786.502 & 1127.41 & 864.77 & 747.193 & 901.5 & 1055.81 \\
\hline & St Dev of & 250.234 & 385.033 & 155.198 & 381.812 & 216.822 & 132.774 & 224.771 & 196.948 & 320.28 & 205.159 & 292.191 & 268.036 & 201.079 & 252.438 & 303.797 \\
\hline \multirow[t]{4}{*}{ New Order Complete } & Minimum Time in System & 118.778 & 120.831 & 89.3763 & 140.618 & 50.6999 & 125.971 & 135.175 & 77.1459 & 135.093 & 41.1831 & 84.4248 & 47.9492 & 73.8333 & 97.2704 & 120.708 \\
\hline & Average Time in System & 449.72 & 798.277 & 421.407 & 466.619 & 287.451 & 421.809 & 545.986 & 632.157 & 711.939 & 502.418 & 489.008 & 457.39 & 426.79 & 515.348 & 603.906 \\
\hline & Maximum Time in System & 889.074 & 1952.15 & 751.974 & 977.49 & 697.174 & 751.462 & 1018.49 & 1453.42 & 1615.73 & 871.749 & 1075.73 & 952.967 & 837.181 & 1083.95 & 1330.72 \\
\hline & St Dev of & 184.479 & 546.814 & 224.745 & 270.137 & 169.547 & 147.361 & 253.624 & 384.125 & 405.047 & 242.381 & 239.736 & 241.344 & 202.893 & 275.778 & 348.664 \\
\hline
\end{tabular}




\section{Blockchain-Driven Customer Order Management}

\section{TABLE VI}

Simulation results: comparison of Current, Transition (1 yr.) and Mature (5yrs) scenarios of Blockchain in customer order management

\begin{tabular}{|l|rrr|l|}
\hline & \multicolumn{3}{|c|}{ Initial } & \multicolumn{2}{|c|}{ Mature } & \\
& Current State & Blockchain State & Blockchain State & Unit \\
\hline Utilisation & 5.2 & 3.2 & 2.1 & Employees exact \\
Man hours needed & 194.2 & 116.6 & 77.8 & Man hours \\
Average Time in System for New Order & 515.3 & 238.0 & 22.1 & Minutes \\
Average Time in System for Order Amend & 380.8 & 170.8 & 132.9 & Minutes \\
\hline
\end{tabular}

\begin{tabular}{|l|r|r|l|}
\cline { 2 - 4 } \multicolumn{1}{c|}{} & \multicolumn{2}{c|}{ Transition to } & \multicolumn{2}{l|}{ Mature } \\
\cline { 2 - 4 } \multicolumn{1}{c|}{} & \multicolumn{2}{|c|}{ Current State } \\
\hline Average Processing for New Order (Hours) & 6.35 & 2.85 & 2.22 \\
Average Processing for Order Amend (Hours) & 3.24 & 1.94 & 1.30 \\
\cline { 2 - 5 } Reduction in Processing Hours New Order & & $55 \%$ & $65 \%$ \\
Reduction in Processing Hours Order Amend & & $40 \%$ & $60 \%$ \\
\hline Account Coordinators Needed & 5.2 & 3.2 & 2.2 \\
Rounded up & 6 & 3.5 & 3 \\
IT expert & 0 & 0.5 & 0.5 \\
\hline Total Employees & 6 & 4 & 3.5 \\
\hline
\end{tabular}

